\title{
Optimal Selection of Development Scheme of Water Resources by Ecological Grey Fuzzy Risk Analysis
}

\author{
Rongyong $\mathrm{Ma}^{1,}$, Yunpeng Zou and Liangguo Xia ${ }^{\mathrm{b}}$ \\ ${ }^{1}$ College of Civil Engineering and Architecture, Guangxi University, Nanning, China, 530004 \\ aemail: mry57@gxu.edu.cn \\ bemail: 454264077@qq.com
}

\begin{abstract}
Keywords: Water conservancy and hydropower engineering; ecological risk; fuzzy theory; grey correlation; ecological restoration; life cycle

Abstract. Firstly, the fuzzy comprehensive is made for each risk factor of large-scale water conservancy and hydropower engineering in its life cycle's each stage, and the fuzzy comprehensive evaluation vector is transformed into fuzzy scores, total risk of ecosystem in different development scale and value of risk factors in a life cycle each stage are calculated. Then, it is calculated that gray correlation degree of each stage and each risk factors by gray theory, and the key risk factors are determined according to the size of the correlation. Third, according to the risk of different ecosystem development scale, using the gray system theory, a relationship of reservoir normal water levels and ecological risk values is established, and prediction of ecological risk is made on the basis of this relationship. Finally, the development scale optimization model considering ecological restoration cost and ecological risk are established and are solved, water resources engineering optimal development scale is ascertained.
\end{abstract}

\section{Introduction}

Water resources and hydropower engineering brings some comprehensive benefits, such as power generation, flood control, irrigation, shipping business, and so on, but the ecological environment would be caused a series of negative effects. In current general environmental impact assessment report, the impact of the ecological environment just be descripted qualitatively, it would cause people lack of evaluating to the ecological environment impact, which only pay attention to economic interests, constructs without full of consideration, then it would bring irreversible ecological problems. Therefore, in the environmental impact assessment of water resources and hydropower engineering, the value of ecological environment should be accounted, analyzing the engineering feasibility on the basis of the comprehensive social, economic and environmental benefits. In order to solve this problem, this paper presents a water resources engineering development scale optimization model, which has comprehensively considered including water resources and hydropower engineering benefit, ecological restoration cost and ecological risk.

Set up water resources engineering development scale optimization model considering the ecological risk

\section{The determination of main ecological risk factors}

Water resources and hydropower engineering ecological risk system level [1,2,3,4,5] are shown in Fig. 1.

Assuming the number of system risk factor is $\mathrm{g}$, the number of development plan is $\mathrm{n}$, and then you can get the total risk vector: $R=\left[\begin{array}{llll}r_{1} & r_{2} & \mathrm{~L} & r_{n}\end{array}\right]$ and risk value vector of various risk factors: $R_{1}^{\prime}=\left[\begin{array}{llll}r_{11}^{\prime} & r_{12}^{\prime} & \mathrm{L} & r_{1 n}^{\prime}\end{array}\right], R_{2}^{\prime}=\left[\begin{array}{llll}r_{21}^{\prime} & r_{22}^{\prime} & \mathrm{L} & r_{2 n}^{\prime}\end{array}\right], \ldots, R_{g}^{\prime}=\left[\begin{array}{llll}r_{g 1}^{\prime} & r_{g 2}^{\prime} & \mathrm{L} & r_{g n}^{\prime}\end{array}\right]$. Regarding $R$ as a standard data array, $\left.{ }^{\prime}{ }_{\mathrm{j}}^{\prime}=1,2, \ldots, \mathrm{g}\right)$ as a being compared data array. At the moment, you can use the theory of gray correlation analysis to work out the degree of association of each risk factor $\gamma_{i}(\mathrm{i}=1$, 
$2, \ldots, \mathrm{g}$ ), and then, carries on the comparison to the degree of association, the greater size of the degree plays the more important role, which can determine the main risk factors.

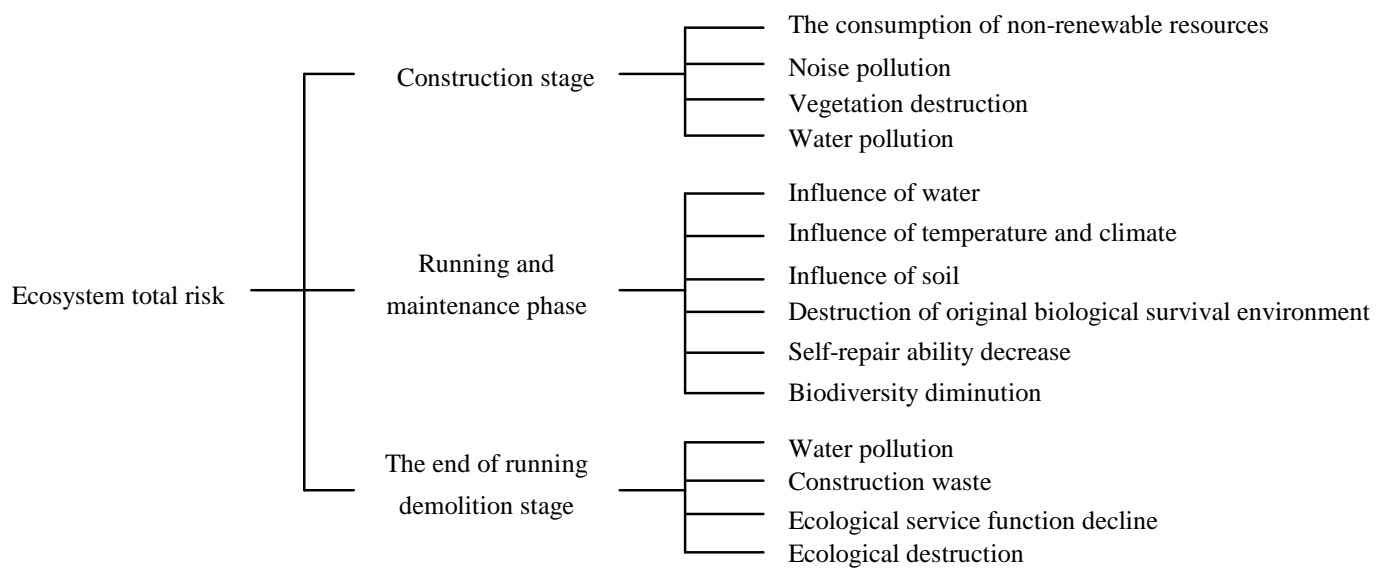

Fig. 1 the level of ecological risk system of water resources and hydropower engineering

\section{The determination of major ecological risk causes}

Assuming a certain risk factor found in p risk causes [6,7], you can get the risk factors vector $R^{\prime}=\left[\begin{array}{llll}r_{1}^{\prime} & r_{2}^{\prime} & \mathrm{L} & r_{n}^{\prime}\end{array}\right]$ and the risk value vector of each individual risk cause: $R_{1}^{\prime \prime}=\left[\begin{array}{llll}r_{11}^{\prime \prime} & r_{12}^{\prime \prime} & \mathrm{L} & r_{1 n}^{\prime \prime}\end{array}\right], R_{2}^{\prime \prime}=\left[\begin{array}{llll}r_{21}^{\prime \prime} & r_{22}^{\prime \prime} & \mathrm{L} & r_{2 n}^{\prime \prime}\end{array}\right], \ldots, R_{p}^{\prime \prime}=\left[\begin{array}{llll}r_{p 1}^{\prime \prime} & r_{p 2}^{\prime \prime} & \mathrm{L} & r_{p n}^{\prime \prime}\end{array}\right]$. Regarding $R^{\prime}$ as a standard data array, $\left.{ }^{\prime \prime}{ }_{\mathrm{j}}^{\prime \prime}=1,2, \ldots, \mathrm{g}\right)$ as a being compared data array. At this moment, you can use the theory of gray correlation analysis to work out the degree of association of each risk cause $\gamma_{i}$ (i=1, $2, \ldots, \mathrm{g}$ ), and then, carries on the comparison to the degree of association, the greater size of the degree plays the more important role, which can determine the main risk causes.

\section{The prediction of the total ecological risk change}

Assuming that have identified $n$ fuzzy risk values of the scale of development, then you can build the fuzzy risk value GM $(1,1)$ model which is growing along with the water level, and predicte by grey theory.

Water resources engineering development scale optimization model considering the ecological risk

(1) Hypothesis of $\mathrm{n}$ development schemes comparison by different normal storage level ( $h=\left[\begin{array}{llll}h_{1} & h_{2} & \mathrm{~L} & h_{n}\end{array}\right]$ ) to reflect the difference of development scale. First of all, calculate the benefit and ecological restoration cost of each development plan, thus you can get three vectors as follow: benefit vector $B=\left[\begin{array}{llll}b_{1} & b_{2} & \mathrm{~L} & b_{n}\end{array}\right]$, the engineering cost vector $C=\left[\begin{array}{llll}c_{1} & c_{2} & \mathrm{~L} & c_{n}\end{array}\right]$ and ecological restoration cost vector $D=\left[\begin{array}{llll}d_{1} & d_{2} & \mathrm{~L} & d_{n}\end{array}\right]$.

(2) According to the aforementioned calculation method to work out the system total risk value of each scheme, then, you can get a fuzzy risk vector $R=\left[\begin{array}{llll}r_{1} & r_{2} & \mathrm{~L} & r_{n}\end{array}\right]$.

(3) Using the regression fitting to find out the benefit as a function of the normal storage level, expressed in $E B(h)$; engineering cost as a function of the normal storage level, expressed in $\mathrm{C}(h)$; ecological restoration cost as a function of the normal storage level, expressed in $D(h)$; fuzzy risk value as a function of the normal storage level, expressed in $R(h)$.

(4) Combining the four functions from the fore step together, you can get new single objective and multi-objective functions $[8,9,10]$ : 


$$
\begin{aligned}
& F_{1}(h)=E B(h)-C(h) \\
& F_{2}(h)=E B(h)-C(h)-D(h) \\
& F_{3}(h)=\frac{E B(h)-C(h)-D(h)}{R(h)}
\end{aligned}
$$

(5) Establish optimization model

Objective function:

$\operatorname{Max}: F_{i}(h)$.

Constraint conditions:

$C(h)-E B(h)<0$

$C(h)+D(h)-E B(h)<0 ;$

$-R(h)<0$

$h_{\min }<h<h_{\max }$.

(6) Using the theory of optimization to work out the extreme value of the fore three functions, the normal storage level which corresponding to the extreme value of the function is expressing the most optimal scale of development. By comparing the optimal normal storage level of development scale of single objective and multi-objective, you can select the optimal normal storage level.

\section{Based on the ecological risk of Baise reservoir normal storage level optimization selection}

\section{Project profile}

Baise hydro-junction is a large-scale hydro project which is given priority to flood control and other comprehensive benefits, such as power generation, irrigation, shipping business, water supply, and so on. The catchment area above the dam site is about $19600 \mathrm{~km}^{2}$, the average flow rate of many years is $263 \mathrm{~m}^{3} / \mathrm{s}$, and annual runoff is 8.29 billion $\mathrm{m}^{3}$. The normal storage level is $228 \mathrm{~m}$, the corresponding capacity is 4.8 billion $\mathrm{m}^{3}$; The design flood level of main dam is $229.66 \mathrm{~m}$, the maximum flood level is $231.49 \mathrm{~m}$, the corresponding total capacity is 5.6 billion $\mathrm{m}^{3}$; Flood limit water level is $214 \mathrm{~m}$, the flood control capacity is 1.64 billion $\mathrm{m}^{3}$, dead water level is $203 \mathrm{~m}$, the corresponding dead reservoir capacity is 2.18 billion $\mathrm{m}^{3}$; The reservoir regulation capacity is 2.62 billion $\mathrm{m}^{3}$. It is an incomplete multi-year regulating storage reservoir.

\section{The calculation of ecosystem total risk in different development scales}

\section{Set up the scale of development}

After analysis, the normal storage level of Baise project could be chosen between 223 233 m, therefore, you can set 6 normal storage levels to represent different development scale in this range. They could be denoted as follows:

$$
\mathrm{H}=\left[\begin{array}{llll}
h_{1} & h_{2} & \mathrm{~L} & h_{6}
\end{array}\right]=\left[\begin{array}{llllll}
223 & 225 & 227 & 229 & 231 & 233
\end{array}\right] \text {. }
$$

\section{The fuzzy matrix of ecosystem total risk in different development scales}

Establish evaluation object factor set and evaluation set, and the fuzzy matrix of risk factors in different development scales; According to the fuzzy matrix and the weight of the risk causes, you can find out the risk factors of fuzzy matrix by using fuzzy transform arithmetic. According to the fuzzy 
matrix and the weight of risk factors, ecological total risk fuzzy matrix could be calculated by fuzzy transform arithmetic in the different development scales.

The fuzzy comprehensive evaluation matrix of ecosystem total risk in different development scales

According to the fuzzy matrix of ecosystem total risk and the corresponding weights, the fuzzy comprehensive evaluation matrix of ecosystem total risk could be calculated by fuzzy transform arithmetic.

The fuzzy score of ecosystem total risk in different development scales

The calculation results of the fuzzy score of ecosystem total risk in different development scales are shown in Table 1.

Table 1 the total risk score corresponding to different normal storage level

\begin{tabular}{cccccccc}
\hline $\mathrm{H}(\mathrm{m})$ & 223 & 225 & 227 & 229 & 231 & 233 \\
\hline $\mathrm{R}$ & 0.4798 & 0.4850 & 0.4916 & 0.4991 & 0.5121 & 0.5273 \\
$\Delta \mathrm{R}$ & 0.0052 & 0.0066 & 0.0075 & 0.0130 & 0.0152 \\
\hline
\end{tabular}

From the results, the total risk fuzzy scores $\mathrm{R}$ increases with the rise of water level. By the incremental risk as you can see that below the water level $229 \mathrm{~m}$, the growing rate of risk is small by the increase of water level; above the water level $229 \mathrm{~m}$, the growing rate of risk increase significant by the increase of water level. Overall, the growing rate of risk is accelerating.

\section{The curve of ecological risk factors and storage water levels}

Using the least squares to fit the relationship curve of ecological total risk and storage water level $(\mathrm{R} \sim \mathrm{h})$ :

$$
R=0.0003 h^{2}-0.1219 h+13.88831 \text {. }
$$

The relationship curve of construction stage risk value and storage water level $\left(\mathrm{R}_{1} \sim \mathrm{h}\right)$ :

$$
R_{1}=0.0004 h^{2}-0.1719 h+19.1451 \text {. }
$$

The relationship curve of running and maintenance phase risk value and storage water level $\left(\mathrm{R}_{2} \sim\right.$ h):

$$
R_{2}=0.0002 h^{2}-0.0705 h+8.3238 .
$$

The relationship curve of the end of running demolition stage risk value and storage water level ( $\mathrm{R}_{3}$ $\sim \mathrm{h})$ :

$$
R_{3}=0.0004 h^{2}-0.1740 h+19.7459 .
$$

According to fit the curve of the storage water level and the total ecological risk curve, the curve of the storage water level and construction stage risk, the curve of the storage water level and running and maintenance phase risk and the curve of the storage water level and the end of running demolition stage risk, you can work out both the ecological total risk of any scale of development in a certain range, and the risk value of any phase in a lifecycle of any scale of development in a certain range of this project. 


\section{The determination of the main ecological risk causes}

According to the fuzzy evaluation algorithm and the method of fuzzy score, you can determine the fuzzy score of ecological risk factors in different development scales. The results are shown in Table 2.

Table 2 the fuzzy scores of ecological risk factors corresponding different normal storage water level schemes

\begin{tabular}{ccccccc}
\hline $\mathrm{H}(\mathrm{m})$ & 223 & 225 & 227 & 229 & 231 & 233 \\
\hline $\mathrm{R}_{1}$ & 0.3702 & 0.3824 & 0.3932 & 0.4070 & 0.4216 & 0.4483 \\
$\mathrm{R}_{2}$ & 0.5484 & 0.5500 & 0.5548 & 0.5559 & 0.5675 & 0.5708 \\
$\mathrm{R}_{3}$ & 0.4762 & 0.4805 & 0.4847 & 0.4981 & 0.5121 & 0.5261 \\
\hline
\end{tabular}

According to fuzzy evaluation algorithm and the method of fuzzy score, you can determine various risk causes of fuzzy score in different development scales. With the analysis of ecological risk of the life cycle of Baise project, including the construction phase, operation and maintenance phase and the final demolition stage, you could be concluded that: in the construction phase, the consumption of non-renewable resources is the most adverse risk causes; in operation and maintenance stages, the original biological habitat destruction as the most unfavorable risk causes; in the final demolition stage, the decline of ecological service function is the most unfavorable risk causes. In the construction phase of the consumption of non-renewable resources, you should try to reduce the limited natural fuel and slow renewable materials, the development and utilization of natural renewable materials, environmental protection and rapid regeneration. In the aspect of operation maintenance phase of the original biological habitat destruction, you should try to protect the original biological habitat, try to avoid homogenization and discontinuous in the form of rivers, advocate the ecological water conservancy. To the final demolition stage of ecological service function decline, you should not only see the directly tangible benefits of water conservancy projects including water supply, irrigation, power generation, and so on, in the feasibility study stage, but also pay more attention about the negative effects which because of the water conservancy engineering change the morphological diversity of river ecosystem, and long-term contact damages to human interests.

\section{The grey prediction of ecological total risk}

According to the calculation method of fuzzy comprehensive score, you could find out total ecological risk value $R_{y i}(i=1,2, \mathrm{~L}, m)$ firstly. And then, establish the relationship between the water level $h_{i}(i=1,2, \mathrm{~L}, m)$ and total ecological risk value $R_{y i}(i=1,2, \mathrm{~L}, m)$ to predict the risk. $R_{y i}$ could be regarded as a part of the known information of which change according to the rise of the water level, but the this dynamic tendency still contain some unknown information. That's to say, the substantive characteristic of this dynamic tendency is gray. Therefore, you can use the modeling mechanism and method of differential equation of grey system to establish the GM $(1,1)$ model.

This paper of grey prediction model is established as:

$$
R=0.0661037 e^{0.00886854 h} .
$$

According to the above model, you can be concluded that the ecological risk in different development scales, as shown in Table 3.

Table 3 ecological risk scores corresponding different normal storage levels

\begin{tabular}{ccccccc}
\hline $\mathrm{H}(\mathrm{m})$ & 223 & 225 & 227 & 229 & 231 & 233 \\
\hline $\mathrm{R}_{\mathrm{y}}$ & 0.4798 & 0.4850 & 0.4916 & 0.4991 & 0.5121 & 0.5273 \\
\hline
\end{tabular}




\section{The calculation of benefits and costs in different construction scales}

For water resources and hydropower engineering development of social economy and ecological environment impact in overall value accounting. Water resources and hydropower engineering of social economy and ecological environment effects include two parts, one is the benefit of the project $\mathrm{EB}$ and itself cost $\mathrm{C}$; the other is the value loss of water resources and hydropower engineering on the ecological environment caused D. Using the method of water resources and hydropower engineering economic analysis, you could find out the benefit, cost and the loss of the ecological environment in different development scale (based on the data in 2000), are shown in Table 4.

Table 4 engineering benefits and costs in different development scale Units: billion Yuan

\begin{tabular}{ccccccc}
\hline $\mathrm{H}(\mathrm{m})$ & 223 & 225 & 227 & 229 & 231 & 233 \\
\hline $\mathrm{EB}$ & 11.248 & 11.784 & 12.136 & 12.326 & 12.408 & 12.447 \\
$\mathrm{C}$ & 4.696 & 4.737 & 4.782 & 4.842 & 4.927 & 5.051 \\
$\mathrm{D}$ & 2.324 & 2.342 & 2.376 & 2.413 & 2.481 & 2.533 \\
\hline
\end{tabular}

Application of regression analysis theory, functions of the normal storage level $\mathrm{h}$ and engineering benefit $\mathrm{EB}$, the normal storage level $\mathrm{h}$ and engineering cost $\mathrm{C}$, the normal storage level $\mathrm{h}$ and ecological restoration costs D could be fitted:

$$
\begin{aligned}
& E B=0.010034 h^{3}-7.0229 h^{2}+1638.5 h-127300 ; \\
& C=0.0023724 h^{3}-1.5972 h^{2}+358.62 h-26807 ; \\
& D=0.0137 h^{2}-6.0241 h+685.2696 .
\end{aligned}
$$

\section{Baise reservoir engineering development scale optimization model}

The engineering development scale optimization model without considering ecological risk:

$$
\begin{aligned}
& F_{1}(h)=E B(h)-C(h) \\
& =0.007662 h^{3}-5.4531 h^{2}+1279.9 h-100493 .
\end{aligned}
$$

Engineering development scale optimization model considering the cost of ecological restoration:

$$
\begin{aligned}
& F_{2}(h)=E B(h)-C(h)-D(h) \\
& =0.007662 h^{3}-5.4394 h^{2}+1285.9 h-101178 .
\end{aligned}
$$

The optimization model for multi-objective engineering development scale considering the ecological risk:

$$
\begin{aligned}
& F_{3}(h)=\frac{E B(h)-C(h)-D(h)}{R(h)} \\
& =\frac{0.007662 h^{3}-5.4394 h^{2}+1285.9 h-101178}{0.0003 h^{2}-0.1219 h+13.88831} .
\end{aligned}
$$

The problems of these models' optimization are constrained nonlinear programming problem. Complex method has been used to solve this problem, solving steps are omitted. The results are as follows: 
When $\mathrm{h}=229.1 \mathrm{~m}, F_{1}(h)$ to obtain the maximum value. So $\mathrm{h}=229.1 \mathrm{~m}$ is the reservoir optimal normal storage level which only considered engineering benefit and cost.

When $\mathrm{h}=228.3 \mathrm{~m}, F_{2}(h)$ to obtain the maximum value. So $\mathrm{h}=228.3 \mathrm{~m}$ is the reservoir optimal normal storage level which considered engineering benefit, cost and ecological restoration cost.

When $\mathrm{h}=227.4 \mathrm{~m}, F_{3}(h)$ to obtain the maximum value. So $\mathrm{h}=227.4 \mathrm{~m}$ is he optimal normal storage level which considered engineering benefit, cost, ecological restoration cost and ecological risk.

\section{Conclusions}

As the calculation results of three development scale optimization models that established in this paper can be seen that, in the single objective optimization model of development scale which only considering engineering benefit and cost, the optimal normal storage level of Baise project is $229.1 \mathrm{~m}$, while the actual normal storage level of it is $228 \mathrm{~m}$, the results significantly greater than the actual value. After considering the cost of ecological restoration, the optimal normal storage level turn into $228.3 \mathrm{~m}$, the calculation results is slightly greater than the actual value. In the multi-objective optimization model of development scale which considering the ecological risk, its optimal normal storage level of development scale optimization model is $227.4 \mathrm{~m}$, the calculation results is less than the actual value. According to the analysis of the calculation results, this model is more in line with the actual situation. In the condition of single target which only considering engineering benefit and cost, when the optimal normal storage level below $229.1 \mathrm{~m}$, the greater the water level, the higher income would be; when surpass the optimal normal storage level, engineering costs rise faster, income decreases, on the contrary. After analyzed the multi-objective, due to the total cost of ecological restoration and ecological risk the accelerated trend along with the water level rise, therefore, its development scale compared with the single objective of smaller. In conclusion, from the three model comparison, selecting the optimization storage level of Baise project development scale between $229.1 \mathrm{~m}$ and $227.4 \mathrm{~m}$ is reasonable.

\section{Acknowledgements}

This work was financially supported by National Natural Science Foundation of China (51369005), Systemic research project of Guangxi key laboratory of Disaster Prevention and Engineering Safety, Guangxi University, Nanning, China (2013ZDX04).

\section{References}

[1] L. Han and Z.J. Dai: Study on Ecological Risk Assessment [J] (In Chinese). Environmental Science Trends, 2001(3): 7-10;

[2] T.B. Xu, H.B. Gu and W.Y. Wang: Calculation Methods of Influence of Ecological Environment on Water and Hydropower Work [J] (In Chinese). Water Power, 2016, 42(2): 1-3;

[3] X.H. Xu, J. Cao and F. Li: Research of Complex Ecological Environment Risk Evaluation System Large of Hydropower Engineering [J] (In Chinese). Project Management Technology, 2010, 8 (12): 17-21;

[4] J.L. Jin, L.B. Zhang, S.W. Zhang and J. Ding. Application of Analytic Hierarchy Process to Environmental Impact Assessment of Water Resources Project [J] (In Chinese). Systems Engineering-theory Methodology Applications, 2004, 13(2): 187-192;

[5] Y. Qiang, Y.X. He and G.H. Liu. Construction Risk Assessment of Small and Medium-sized Water Conservancy and Hydroelectric Power Engineering Based on Fuzzy Analytic Hierarchy Method [J] (In Chinese). Construction Technology, 2013, 42(21): 51-54; 
[6] Zbigiew W Kundzewicz. New Uncertainty Concepts in Hydrology and Water Resources [M]. Cambridge University Press, 2001. 1-23;

[7] G.R. Luo. Multiple Standards Hydropower Project Economic Evaluation Risk Second-order Range Estimates [J] (In Chinese). Shuili Xuebao, 1993(12): 55-60;

[8] Y.Z. Tian and Z.G. Zheng. Approach to Method of Ascertaining Weight in Life Cycle Impact Assessment [J] (In Chinese). Journal of Chongqing Jianzhu University, 2003, 25(5): 61-64;

[9] L.S. Yu, S. Liu and J. Wang. Calculation Methods of Influence of Ecological Environment on Water and Hydropower Works [J] (In Chinese). Water Resources \& Hydropower of Northeast, 2000, 18(189): 1-3;

[10] Z.F. Sun and Z.C. Dong. Analysis of Water Resources Ecological Economic Value Model [J] (In Chinese). Automation in Water Resources and Hydrology, 2005(1): 10-13.

\section{Bibliography}

Rongyong Ma (1955- ), male, the Zhuang nationality, professor, Nanning, China. E-mail: mry57@gxu.edu.cn. 